\title{
Produtividade e qualidade de frutos do mamoeiro em função de tipos e doses de biofertilizantes ${ }^{1}$
}

\section{Yield and fruit quality of papaya as function of types and levels of biofertilizers}

\author{
Evandro Franklin de Mesquita ${ }^{2}$; Lourival Ferreira Cavalcante ${ }^{3,6 *}$; \\ Saulo Cabral Gondim ${ }^{3}$; Ítalo Herbert Lucena Cavalcante ${ }^{4,7}$; \\ Fernanda Aspazia Rodrigues de Araújo ${ }^{5}$; Márkilla Zunete Beckmann-Cavalcante ${ }^{7}$
}

\section{Resumo}

Os biofertilizantes são produtos orgânicos geralmente obtidos via anaerobiose, estudados, principalmente, como fitoprotetores para a agricultura, mas que podem também incrementar a produção das plantas. Nesse sentido, um experimento de campo foi desenvolvido, no período de maio/2003 a agosto/2004, no município de Remígio-Pb, para avaliar os efeitos de dois biofertilizantes bovinos sobre a massa média, produtividade e a qualidade externa e interna dos frutos do mamoeiro Havaí (Carica papaya $\mathrm{L}$.) cultivar 'Baixinho de Santa Amália'. Os tratamentos foram dispostos em blocos casualizados com três repetições e 15 plantas por parcela, em esquema fatorial 2 x 5 ,sendo dois biofertilizantes: puro (água e esterco fresco de bovino) e o supermagro (além de água e esterco bovino fresco é enriquecido com macro, micronutrientes e mistura protéica), aplicados ao solo na forma líquida nos volumes 0,$0 ; 0,5$; 1,$0 ; 1,5 ; \mathrm{e} 2,0 \mathrm{~L} \mathrm{cova}^{-1}$. A massa média, a produtividade e as variáveis referentes à qualidade externa e interna dos frutos não deferiram entre os tipos de biofertilizantes, mas responderam significativamente às doses de ambos os insumos. Os resultados, exceto quanto à firmeza dos frutos, demonstram efeitos positivos dos biofertilizantes no cultivo do mamoeiro 'Baixinho de Santa Amália' em termos de rendimento por área e qualidade físico-química dos frutos.

Palavras-chave: Adubação orgânica, Carica papaya L., fertilizante alternativo

\begin{abstract}
Biofertilizers are organic products usually obtained from an anaerobic process, evaluated mainly as phytoprotectors for agriculture, although they can improve fruit production. By this way, a field experiment was carried out in Remígio County, Paraiba State, Brazil, to evaluate the effects of two bovine biofertilizers on yield, medium mass and quality of papaya fruits (Carica papaya L.), 'Baixinho de Santa Amália' cultivar. Treatments were distributed in a randomized complete blocks design with three replications and 15 plants in each parcel, in a $2 \times 5$ factorial arrangement, with two biofertilizers: simple (water and fresh
\end{abstract}

1 Parte da dissertação do primeiro autor.

2 Mestre em Manejo de Solo e Água, CCA/UFPB.

3 Profs. Universidade Federal da Paraíba (UFPB).

4 Prof. Universidade Federal do Piauí (UFPI).

5 Mestranda em Agronomia, CCA/UFPB.

6 Bolsista produtividade científica CNPq. Doutor em Agronomia, Professor da Universidade Federal da Paraíba e pesquisador nível 2 do CNPq. E-mail: lofeca@cca.ufpb.br

7 Doutorando em Produção Vegetal/FCAV/UNESP, Jaboticabal-SP.

* Autor para correspondência 
bovine manure) and supermagro (water, fresh bovine manure, macro and micronutrients and a protein mix), applied in soil under liquid form at five volumes, as follows: $0.0 ; 0.5 ; 1.0 ; 1.5 ; \mathrm{e} 2.0 \mathrm{~L} \mathrm{cave}^{-1}$. There was no statistical difference between biofertilizers for fruit mass, yield and external and internal fruit quality variables, while between volumes differences were registered for both biofertilizers. The results, except for fruit firmness, registered positive effects of the biofertilizers on 'Baixinho de Santa Amália' papaya cultivar in relation to yield and physical and chemical fruit quality.

Key words: Organic fertilization, Carica papaya, alternative fertilizer

\section{Introdução}

O mamoeiro (Carica papaya L.) originário da América Central é uma planta cultivada em regiões tropicais e subtropicais desde o nível do mar até mais de $500 \mathrm{~m}$ de altitude. Essa característica contribui para sua disseminação em quase todo o território brasileiro revelando o Brasil como o País que mais produz mamão em escala mundial (FOOD AND AGRICULTURE ORGANIZATION OF THE UNITED NATIONS, 2006). As regiões Sudeste e Nordeste somam em média $87,5 \%$ da produção brasileira, destacando-se os estados do Espírito Santo e Bahia como os principais produtores destas regiões. No estado da Paraíba a cultura do mamão merece destaque especial, uma vez que a produtividade média é de $47 \mathrm{tha}^{-1}$, portanto superior às médias nordestina, brasileira e mundial que são 44, 45 e $27 \mathrm{t} \mathrm{ha}^{-1}$, respectivamente (IBGE, 2006).

Apesar de possuir condições favoráveis ao cultivo do mamoeiro, o Nordeste brasileiro tem apresentado um decréscimo na produção desta fruta nos últimos anos se comparado com a região Sudeste devido, a vários fatores com problemas fitossanitários, redução de área plantada e elevados custos de insumos e defensivos agrícolas. Por isso se deve considerar a possibilidade de utilização de insumos alternativos, objetivando substituir parcialmente os fertilizantes minerais por produtos orgânicos como biofertilizantes, no manejo agrícola da cultura do mamoeiro no Nordeste do Brasil.

Nesse sentido, vários trabalhos têm sido realizados em diferentes frutíferas como melão (VILLELA JÚNIOR; ARAÚJO; FACTOR, 2003), maracujá (COLLARD et al., 2001; SOUSA et al., 2006) e graviola (FIGUEIREDO, 2003).
Tradicionalmente o cultivo do mamoeiro Havaí tem sido feito de maneira convencional, realizandose adubação mineral via solo quase totalmente com fertilizantes sintéticos como apresentam Marinho et al. (2002) e Gaiva et al. (2002). Entretanto, a partir do inicio da década de 90 tem se registrado, no mundo e inclusive no Brasil, aumento da aplicação de insumos naturais, dentre eles, os biofertilizantes, objetivando a produção de alimentos com menor uso de insumos sintéticos (SANTOS 1992; KHATOUNIAN, 2001; CRUZ et al., 2003; ARAÚJO et al., 2005).

Os efeitos de biofertilizantes aplicados no solo foram estudados por Santos e Mendonça (2000), concluindo que há melhorias nas propriedades físicas a partir da redução da densidade, bem como liberação de ácidos orgânicos (LAGREID; BOCKMAN; KAARSTAD, 1999). Galbiatti et al. (1996) reportaram enriquecimento químico do solo na capacidade de retenção de bases promovido pela aplicação do biofertilizante. Para os autores, esse aspecto exerce relevância, visto que a obtenção de elevado rendimento com qualidade de frutos está diretamente associada a uma nutrição balanceada da cultura, como observaram Leão, Fagundes e Yamanishi (2002) e Oliveira e Caldas (2004) para o mamoeiro. Adicionalmente, deve-se registrar que uma planta bem suprida tem maior tolerância à incidência de pragas e doenças.

O presente trabalho teve como objetivo avaliar a produtividade e qualidade de frutos de mamoeiro 'Baixinho de Santa Amália' tratado com tipos e doses de biofertilizantes bovinos fornecidos via solo na forma líquida. 


\section{Material e Métodos}

\section{Caracterização da área experimental}

$\mathrm{O}$ experimento foi conduzido numa área de transição entre o brejo e a região semi-árida do município de Remígio, Paraíba, localizado nas coordenadas $6^{\circ} 53^{\prime} 00^{\prime \prime}$ de latitude Sul, $36^{\circ} 02^{\prime} 00^{\prime \prime}$ a oeste do meridiano de Greenwich e a uma altitude de $470 \mathrm{~m}$ acima do nível do mar.

O solo no local do experimento é um ARGISSOLO VERMELHO - AMARELO Distrófico arênico (SANTOS et al., 2006). Na profundidade de $0-20 \mathrm{~cm}$ contém 818, 122 e $60 \mathrm{~g} \mathrm{~kg}^{-1}$ de areia, silte e argila respectivamente. A densidade do solo é de $1,55 \mathrm{~g} \mathrm{~cm}^{-3}$ e a de partículas $2,73 \mathrm{~g} \mathrm{~cm}^{-3}$, com porosidade total de $0,43 \mathrm{~cm}^{3} \mathrm{~cm}^{-3}$. Na mesma faixa, o solo possui $\mathrm{pH} \mathrm{em}$ água $(1,0: 2,5)=5,3$, é deficiente em $\mathrm{P}, \mathrm{K}, \mathrm{Ca}, \mathrm{Mg}$ e Fe, com valores de $4 \mathrm{mg} \mathrm{dm}^{-3}$ (P - Merlich - 1); $40 \mathrm{mg} \mathrm{dm}^{-}$ ${ }^{3}$ (K-Merlich - 1); 0,70 $\mathrm{cmol}_{\mathrm{c}} \mathrm{dm}^{-3}(\mathrm{Ca}) ; 0,45 \mathrm{cmol}_{\mathrm{c}} \mathrm{dm}^{-}$ ${ }^{3}(\mathrm{Mg}) ; 4,7 \mathrm{mg} \mathrm{dm}^{-3}(\mathrm{Fe})$ e com teores de $\mathrm{Al}^{+3}$ e $\mathrm{H}+$ $\mathrm{Al}^{+}$de 0,10 e $2,56 \mathrm{cmol}_{\mathrm{c}} \mathrm{dm}^{-3}$, respectivamente (EMPRESA BRASILEIRA DE PESQUISA AGROPECUÁRIA, 1997).

As covas foram abertas nas dimensões de $40 \mathrm{x}$ $40 \times 40 \mathrm{~cm}$, preparadas 30 dias antes do plantio com
$100 \mathrm{~g}$ de fosfato natural (24\% de $\mathrm{P}_{2} \mathrm{O}_{5}$ total e $26 \%$ de $\mathrm{CaO}$ ) e $10 \mathrm{~L}$ de esterco bovino curtido de relação $\mathrm{C} / \mathrm{N}=15: 1$. O plantio do mamoeiro Havaí (Carica papaya $\mathrm{L}$.), cultivar 'Baixinho de Santa Amália', foi feito em maio de 2003, em espaçamento de 2 x $2 \mathrm{~m}$.

\section{Tratamentos e delineamento experimental}

Os tratamentos foram dispostos em blocos casualizados, com três repetições e 15 plantas por parcela, adotando o esquema fatorial $2 \times 5$, referente aos tipos de biofertilizante puro e supermagro aplicados nas doses 0,$0 ; 0,5 ; 1,0 ; 1,5 ; 2,0 \mathrm{~L} \mathrm{cova}^{-1}$ respectivamente. A dose máxima de cada insumo (2,0 L planta-1) foi baseada em Santos (1992) que recomenda a aplicação de $15 \mathrm{~L} \mathrm{~m}^{-2}$ do biofertilizante comum ao solo diluído em água . A aplicação no solo foi realizada manualmente com os biofertilizantes na forma líquida, diluídos em água na proporção 1:3, numa microbacia com área de $0,126 \mathrm{~m}^{2}$, uma semana antes e a cada dois meses após o plantio até o final do experimento. A composição nutricional dos biofertilizantes e as quantidades fornecidas ao mamoeiro por cada dose estão contidas na Tabela 1 .

Tabela 1. Composição nutricional e quantitativa de nutrientes fornecidos em cada dose dos biofertilizantes simples e enriquecido por aplicação $\left(\mathrm{g} \mathrm{dm}^{-3}\right)$.

\begin{tabular}{|c|c|c|c|c|c|c|c|c|c|c|}
\hline \multirow{2}{*}{$\begin{array}{c}\text { Dose } \\
\text { L cova }^{-1}\end{array}$} & \multicolumn{2}{|c|}{$\mathrm{N}$} & \multicolumn{2}{|c|}{$\mathrm{P}$} & \multicolumn{2}{|c|}{ K } & \multicolumn{2}{|c|}{$\mathrm{Ca}$} & \multicolumn{2}{|c|}{$\mathrm{Mg}$} \\
\hline & BS & $\mathrm{BE}$ & BS & $\mathrm{BE}$ & BS & $\mathrm{BE}$ & BS & $\mathrm{BE}$ & BS & $\mathrm{BE}$ \\
\hline $\mathrm{CN}$ & 0,76 & 0,19 & 0,05 & 0,22 & 0,82 & 2,7 & 0,21 & 0,24 & 0,13 & 0,15 \\
\hline 0,0 & - & - & - & - & - & - & - & - & - & - \\
\hline 0,5 & 0,38 & 0,095 & 0,025 & 0,11 & 0,41 & 1,35 & 0,105 & 0,12 & 0,065 & 0,075 \\
\hline 1,0 & 0,76 & 0,19 & 0,05 & 0,22 & 0,82 & 2,7 & 0,21 & 0,24 & 0,13 & 0,15 \\
\hline 1,5 & 1,14 & 0,285 & 0,075 & 0,33 & 1,23 & 4,05 & 0,315 & 0,36 & 0,195 & 0,225 \\
\hline 2,0 & 1,52 & 0,38 & 0,10 & 0,44 & 1,64 & 5,4 & 0,42 & 0,48 & 0,26 & 0,30 \\
\hline
\end{tabular}

$\mathrm{CN}=$ Composição nutricional; $\mathrm{BS}=$ biofertilizante simples; $\mathrm{BE}=$ biofertilizante enriquecido.

\section{Descrição e preparo dos biofertilizantes}

Ambos os biofertilizantes foram obtidos por fermentação anaeróbica em biodigestor. O biofertilizante comum foi produzido misturando-se partes iguais de esterco bovino fresco e água não salina, mantendo-se em fermentação por 30 dias
(SANTOS, 1992). O biofertilizante supermagro (MEIRELLES et al., 1997), além de esterco bovino fresco e água é enriquecido com macro, micronutrientes e mistura protéica. A mistura protéica é constituída de $1 \mathrm{~L}$ de leite, $1 \mathrm{~L}$ de melaço, $100 \mathrm{~mL}$ de sangue de boi, $200 \mathrm{~g}$ de farinha de osso, $200 \mathrm{~g}$ de 
calcário dolomítico (26\% CaO e 14\% MgO), 200 g de fosfato de Araxá $\left(24 \% \mathrm{P}_{2} \mathrm{O}_{5}\right.$ total e $\left.26 \% \mathrm{CaO}\right)$.

A cada dois dias foram feitas adições da mistura protéica juntamente com uma fonte de nutrientes na seguinte ordem: a) $2 \mathrm{~kg}$ de sulfato de zinco (20\% Zn, $16-18 \% \mathrm{~S}$ ); b) $2 \mathrm{~kg}$ de sulfato de magnésio (9\% Mg, $13 \% \mathrm{~S})$; c) $300 \mathrm{~g}$ de sulfato de manganês ( $26 \% \mathrm{Mn}$, $14-15 \% \mathrm{~S})$; d) $300 \mathrm{~g}$ de sulfato de cobre $(13 \% \mathrm{Cu}$, $16-18 \% \mathrm{~S})$; e) $50 \mathrm{~g}$ de sulfato de cobalto $(20 \% \mathrm{Co}$, $11 \% \mathrm{~S})$; f) $300 \mathrm{~g}$ de sulfato de ferro $(19 \% \mathrm{Fe}, 10-$ $11 \% \mathrm{~S}) ; \mathrm{g}) 2 \mathrm{~kg}$ de cloreto de cálcio $(27,2 \% \mathrm{Ca}, 48,3 \%$ Cl); h) $1 \mathrm{~kg}$ de ácido bórico (17\% B); i) 100 g de molibdato de sódio (39\% Mo). Perfazendo ao final nove adições da mistura protéica.

\section{Tratos culturais e colheita}

Foi realizada adubação nitrogenada com uréia $(45 \% \mathrm{~N})$ aplicando-se 30 e $50 \mathrm{~g}$ planta $^{-1}$ de nitrogênio aos 70 e 100 dias e de $100 \mathrm{~g}$ do elemento a partir dos 160 dias após o plantio, a cada dois meses até o final da colheita (OLIVEIRA et al., 2002).

As plantas foram irrigadas pelo método de aplicação localizada por gotejamento, utilizando-se um emissor 'catife', auto compensante às perdas de carga hidráulica, com vazão de $3,75 \mathrm{~L} \mathrm{~h}^{-1}$, fornecendo-se a cada planta uma lâmina de água $20 \%$ superior à lâmina evaporada no dia anterior, obtida de tanque classe A (CRUZ et al., 2003).

A colheita foi feita no período de janeiro a agosto de 2004, quando os frutos apresentavam entre $25 \%$ e $50 \%$ da casca amarelada. No pico da produção, quando todos os tratamentos estavam com frutos, foram coletados aleatoriamente 15 frutos por parcela, para caracterização física e química.

\section{Variáveis observadas e análises estatísticas}

Foram registradas as seguintes variáveis nos frutos: Diâmetro equatorial e comprimento, espessura da casca e firmeza (com casca), rendimento em polpa, teores de sólidos solúveis (SS, em `brix), acidez titulável (AT, em \% de ácido cítrico) e pH da polpa conforme Instituto Adolfo Lutz (1985).
Registrou-se também a massa média dos frutos e produtividade das plantas.

Os dados foram submetidos à análise de variância para avaliação dos efeitos entre os biofertilizantes e os níveis foram submetidos à análise quantitativa de regressão polinomial, conforme recomendações de Ferreira (2000).

\section{Resultados e Discussão}

Não foram registradas diferenças significativas entre biofertilizantes, mas as doses de ambos os insumos influenciaram significativamente a produção e a maioria das variáveis relativas à qualidade dos frutos de mamoeiro. Adicionalmente, as interações entre os tipos e doses de biofertilizante foram significativas.

A massa média máxima de frutos variou entre 476 e $460 \mathrm{~g}$ referentes à mesma dose $\left(1,2 \mathrm{~L} \mathrm{cova}^{-1}\right)$ de cada insumo (Figura 1A). Esses resultados foram superiores aos valores de $320 \mathrm{~g}$ apresentados por Gaiva et al. (2002) e aos 400 e $367 \mathrm{~g}$ registrados por Pastor (2002), respectivamente no primeiro e segundo ano de colheita com o mesmo cultivar em plantio convencional. Foram superiores também aos $302 \mathrm{~g}$ obtidos por Cruz et al (2003) sob cultivo fertirrigado com nitrogênio.

As maiores produtividades calculadas foram de 53.576 e $50.091 \mathrm{~kg} \mathrm{ha}^{-1}$ obtidas com 1,6 e 1,7 L planta $^{-}$ ${ }^{1}$, respectivamente para o biofertilizante comum e supermagro (Figura 1B). Esses resultados são superiores à média Nacional (44.000 $\left.\mathrm{kg} \mathrm{ha}^{-1}\right)$, do Nordeste (45.000 kg ha-1) e mundial (17.000 kg ha-1) como apresentado pelo IBGE (2006). As produtividades alcançadas neste trabalho foram superiores aos $37.128 \mathrm{~kg} \mathrm{ha}^{-1}$ obtidos por Almeida et al. (2002) durante sete meses de colheita com o cultivar Improved Solo 72/12 sob diferentes lâminas de irrigação, entretanto foram inferiores aos 173.000 e $119.970 \mathrm{~kg} \mathrm{ha}^{-1}$ obtidos por Pastor (2002) para o cultivar 'Baixinho de Santa Amália', no primeiro e segundo ciclo da cultura, referente ao período de 10 e 12 meses de colheita, sob cultivo tradicional. 

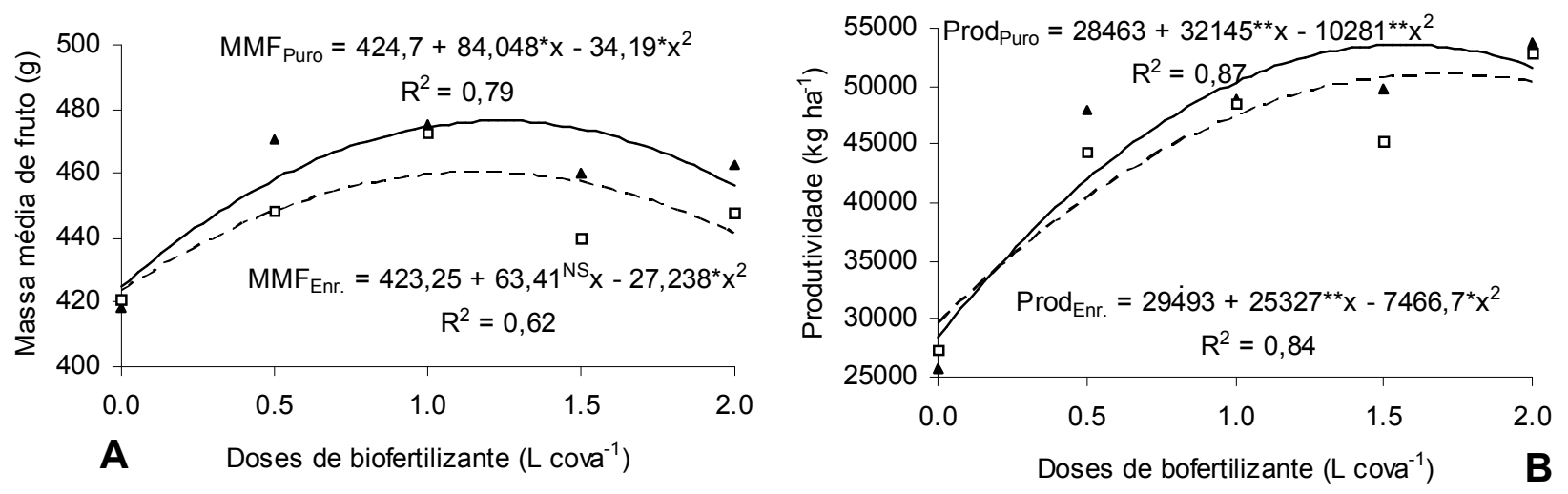

Figura 1. Massa média de frutos (A) e produtividade (B) do mamoeiro 'Baixinho de Santa Amália', em função de fontes e doses de biofertilizantes puro $(-2 \%)$ e enriquecido $(--; \%) * \mathrm{e}^{* *}$ respectivamente significativos para $\mathrm{p}<0,05$ e $\mathrm{p}<0,01$.

Pelos resultados da massa média dos frutos e produtividade (Figura 1A e 1B) e a comparação com a literatura especializada para o mamoeiro, evidenciam-se efeitos positivos das doses dos insumos, aplicados ao solo na forma líquida, para o cultivo do mamoeiro ‘Baixinho de Santa Amália'.

Com base nas regressões, a maior média calculada de comprimento dos frutos foi $132 \mathrm{~mm}$, obtida com a dose de 1,3 $\mathrm{L}_{\text {planta }}{ }^{-1}$ para ambos os insumos (Figura 2A). Os valores são inferiores aos $156 \mathrm{~mm}$ de Miranda et al. (2002) em estudo com o mesmo cultivar.

Quanto ao diâmetro, os maiores valores calculados foram 92 e $97 \mathrm{~mm}$ obtidos em frutos de plantas submetidas à uma mesma dose dos dois biofertilizantes, 1,4 L planta $^{-1}$ (Figura 2B), portanto superaram os 84 e $87 \mathrm{~mm}$ registrados por Marinho et al. (2001) em frutos de mamoeiro do grupo Solo, mas são inferiores aos $107 \mathrm{~mm}$ em frutos do cultivar 'Baixinho de Santa Amália' registrados por Miranda et al. (2002).

A espessura da casca dos frutos cresceu linearmente com o aumento das doses do biofertilizante comum, na ordem de $0,34 \mathrm{~mm}$ por litro do insumo aplicado ao solo (Figura 2C). Os valores variaram de 2,28 a 2,94 mm, com média de 2,54 mm. Nos tratamentos com o biofertilizante supermagro, os valores da espessura da casca que resultaram na média de 2,69 mm, não se ajustaram a nenhum modelo matemático (Figura 2C). Os resultados, em ambos os casos estão coerentes com os 2,6 mm obtidos por Miranda et al. (2002) em frutos do cultivar 'Baixinho de Santa Amália'.

Apesar da espessura da casca estar compatível ao transporte dos frutos para longas distâncias, as maiores firmezas foram de 0,50 e $0,52 \mathrm{~kg} \mathrm{~cm}^{-2}$, referentes às doses de 1,3 e 1,5 $\mathrm{L}$ planta $^{-1}$ para os dois tipos de insumos utilizados (Figura 2D), valores considerados baixos por Fagundes e Yamanishi (2001). Possivelmente essa situação seja atribuída ao estádio de maturação, uma vez que os frutos foram colhidos quando estavam com 50 e $70 \%$ da casca amarela, isto é, próximo do ponto de maturação para consumo ao natural. Frutos com baixa firmeza são mais susceptíveis aos danos físicos que reduzem a vida útil para efeitos da comercialização. Comparativamente, os resultados foram expressivamente inferiores aos $0,80 \mathrm{~kg} \mathrm{~cm}^{-2}$ avaliados por Fagundes e Yamanishi (2001), em frutos de mamão do grupo Solo; entretanto semelhantes aos $0,48 \mathrm{~kg} \mathrm{~cm}^{-2}$ apresentados por Miranda et al. (2002) em mamão cv 'Baixinho de Santa Amália', produzido sob a forma convencional de cultivo. 

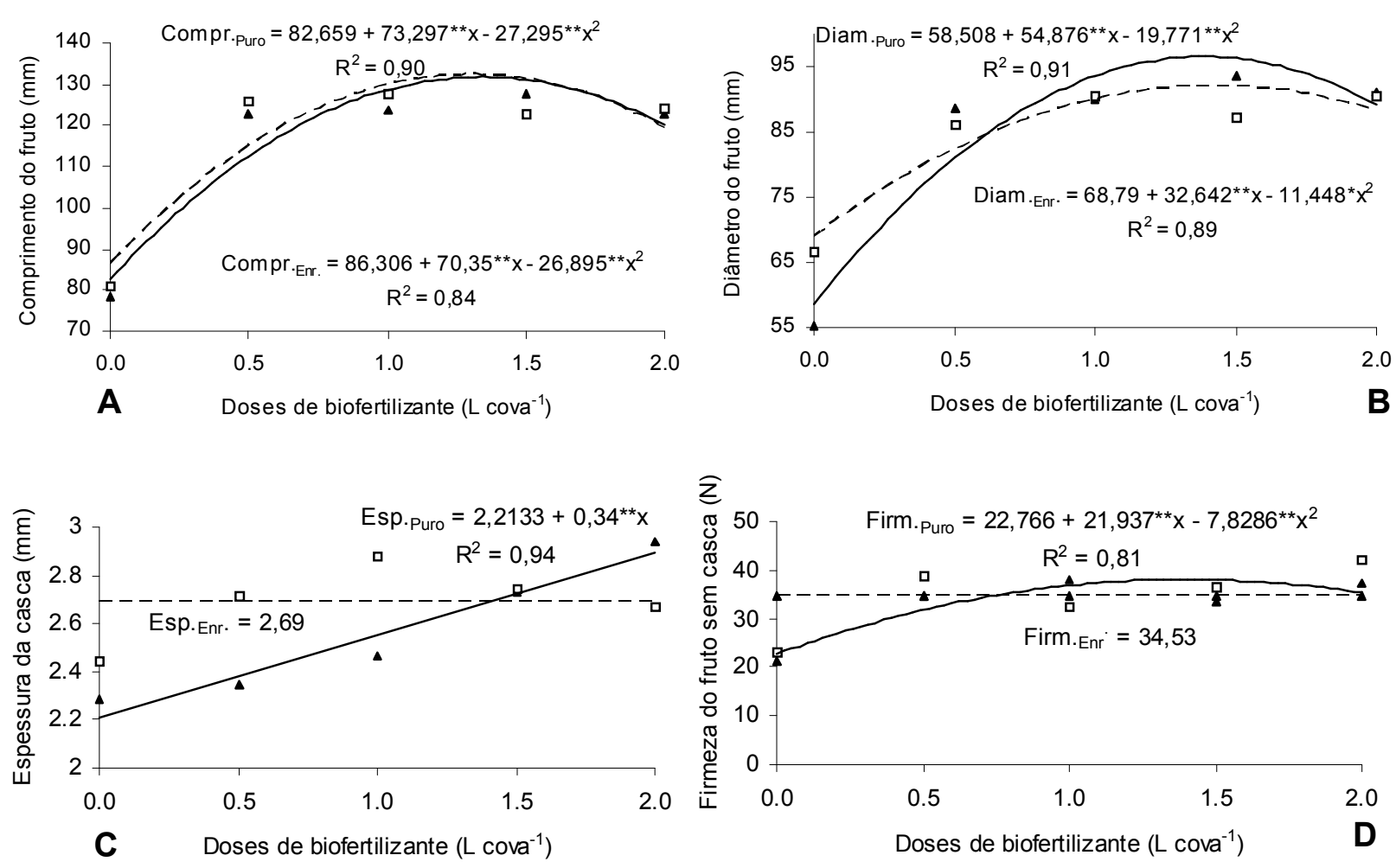

Figura 2. Comprimento (A), diâmetro(B), espessura da casca de frutos (C) e firmeza do fruto com casca (D) de mamoeiro 'Baixinho de Santa Amália' em função de fontes e doses de biofertilizantes puro (—2\%) e enriquecido (--- ¡\%).

Exceto a acidez titulável (Figura 3C), o rendimento em polpa, os teores de sólidos solúveis - ${ }^{\circ}$ brix (SST) e o pH da polpa (Figura 3A, B, D) não se adequaram significativamente a nenhum modelo de regressão.

Os rendimentos médios em polpa dos frutos foram de $64,46 \%$ (bioferlitizante Comum) e $64,18 \%$ (biofertilizante Supermagro), conforme apresentado na Figura 3A; assim marcadamente superiores aos 36,7 \% obtidos por Medina et al. (1980). Os maiores teores de sólidos solúveis (SS) variaram de 12,53 a 13 brix, referentes aos tratamentos com biofertilizante comum e o supermagro, respectivamente (Figura 3B). Esses resultados estão coerentes com as exigências do mercado de frutos do grupo Solo que são da ordem de $11,5^{\circ}$ brix (FAGUNDES; YAMANISHI, 2001), inclusive superiores aos 8,8 ${ }^{\circ}$ brix de frutos do 'Baixinho de Santa Amália' apresentados por Miranda et al. (2002) e semelhantes aos valores de 13,5; 13,0 e 13,8 ${ }^{\circ}$ brix de cultivares do grupo Solo, reportados por Marinho et al. (2002), ambos sob a forma convencional de manejo da cultura..
A acidez titulável (AT) não variou significativamente com os tipos de biofertilizantes, mas aumentou linearmente com as doses de ambos os insumos fornecidos ao solo na forma liquida (Figura $3 C)$. Os dados oscilaram de 0,043 a $0,056 \%$ nas plantas tratadas com biofertilizante puro e de 0,046 a $0,056 \%$, nas tratadas com o supermagro, apresentando-se, portanto, adequados ao mercado consumidor conforme Marinho et al.(2002) e Araújo et al.(2005). Apesar do aumento em função das doses aplicadas, os resultados foram inferiores ao valor médio obtido por Fagundes e Yamanishi (2001), que foi de $0,07 \%$ em mamão do grupo Solo.

As médias do $\mathrm{pH}$ na polpa referentes às doses entre ambos os biofertilizantes foram basicamente às mesmas, 5,40 e 5,38, em frutos colhidos com $50 \mathrm{e}$ $70 \%$ da casca amarela, próximo do ponto de consumo à mesa ou ao natural (Figura 3D). Os valores situamse no mesmo patamar registrado por Fagundes e Yamanishi (2001), Miranda et al. (2002) bem como por Marinho et al. (2002) e estão dentro da faixa adequada para o consumo na forma de fruto fresco 

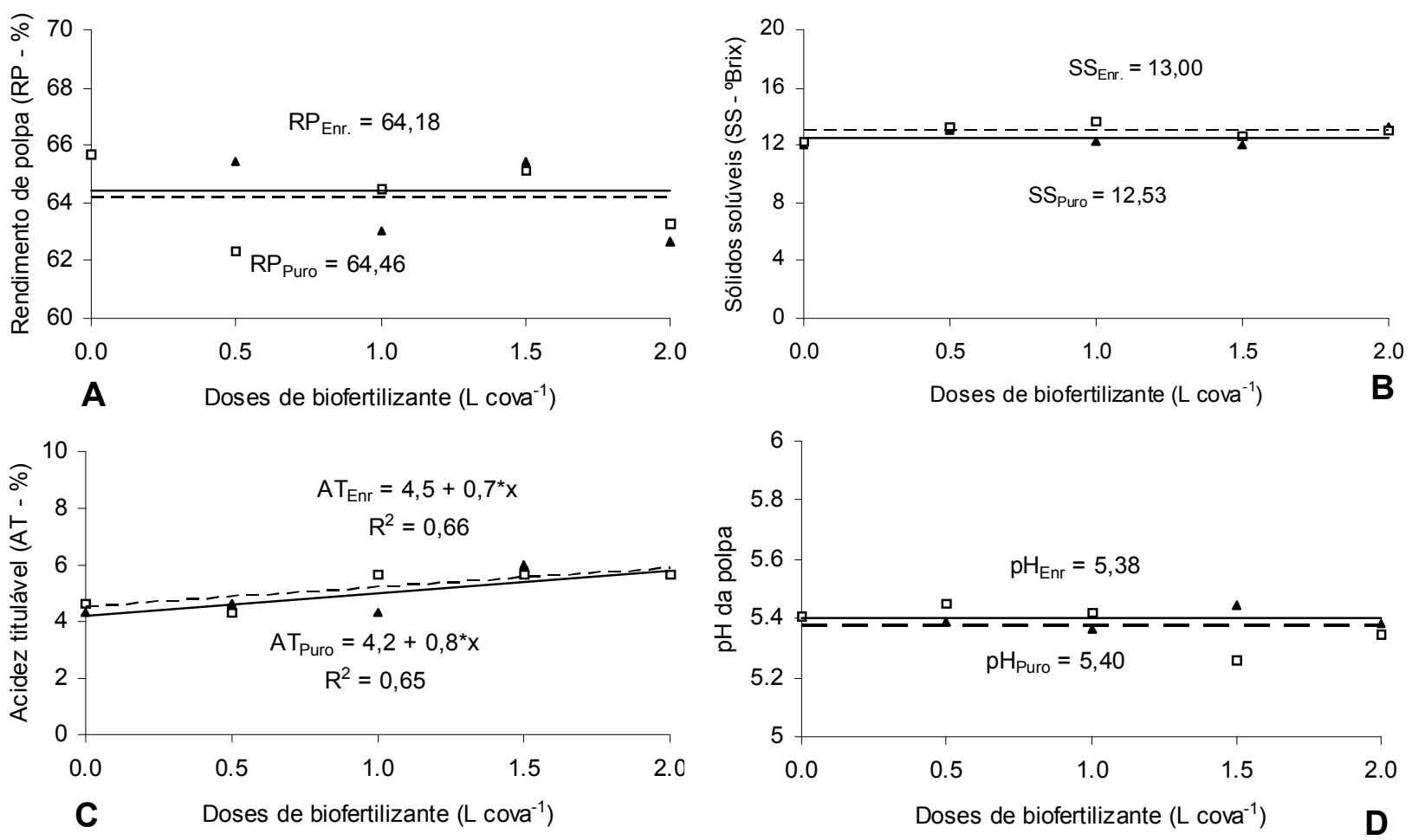

Figura 3. Rendimento de polpa (A), sólidos solúveis (B), acidez titulável (C) e pH da polpa e de frutos de mamoeiro (D) 'Baixinho de Santa Amália', em função de fontes e doses de biofertilizantes puro (-2\%) e enriquecido (--- ¡\%).

\section{Conclusões}

Não há diferença entre os tipos de biofertilizantes quanto aos efeitos sobre produção e qualidade físicoquímica dos frutos de mamoeiro;

Doses crescentes de biofertilizante influenciam a massa média, os atributos externos avaliados pelo comprimento e diâmetro dos frutos, bem como a acidez titulável, dentre as características internas.

O mamoeiro produz frutos compatíveis às exigências do mercado consumidor sob fertilização do solo em cobertura com biofertilizantes.

\section{Referências}

ALMEIDA,F. T.; BERNADO, S.; MARINHO, C. S.; MARIN, S. L. D.; SOUSA, E. F. Teores de nutrientes do mamoeiro Improved Sunrise Solo 72/12 sob diferentes lâminas de irrigação no norte Fluminense. Revista Brasileira de Fruticultura, Jaboticabal, v.24, n.2, p.547-551, 2002.

ARAÚJO, F. A. R.; MESQUITA, E. F.; CAVALCANTE, L. F.; GONDIM, S. C.; DANTAS, T. A.; CAVALCANTE, I. H.
L. Composição de macronutrientes em folhas de mamoeiro desenvolvido em solo com biofertilizante líquido. In: MARTINS, D. S. (Ed.). Papaya Brasil: mercado e inovações tecnológicas para o mamão. Vitória: INCAPER, 2005. p.355-358.

COLLARD, F. H.; ALMEIDA, A.; COSTA, M. C. R.; ROCHA, M. C. Efeito do uso de biofertilizante agrobio na cultura do maracujazeiro amarelo (Passiflora edulis $\mathrm{f}$. flavicarpa Deg). Biociências, Taubaté, v.7, n.2, p.1-7, 2001.

CRUZ, M. C. M.; CAVALCANTE, L. F.; FEITOSA FILHO, J. C.; GONDIM, S. C.; MESQUITA, E. F.; CAVALCANTE, I. H. L. Comportamento do mamoiero Havaí fertirrigado com nitrogênio e plantas pulverizadas com biofetilizante e calda bordaleza. In: CONGRESSO BRASILEIRO DE FERTIRRIGAÇÃO, 1., 2003, João Pessoa. Anais.... João Pessoa: Universidade Federal da Paraíba, 2003. (CDROM).

EMPRESABRASILEIRADEPESQUISA AGROPECUÁRIA -EMBRAPA. Centro Nacional de Pesquisa de Solos. Manual de métodos de analise de solo. 2.ed. Rio de Janeiro: EMBRAPA, 1997. (Documentos, 1).

FAGUNDES, G. R.; YAMANISHI, O. K. Características físicas e químicas em frutos de mamoeiro do grupo solo comercializado em 4 estabelecimentos de Brasília - DF. Revista Brasileira de Fruticultura, Jaboticabal, v.23, n.3, p.541-545, 2001. 
FERREIRA, P. V. Estatística experimental aplicada à agronomia. 3.ed. Maceió: EDUFAL, 2000.

FIGUEIREDO, F. L. Estado nutricional da gravioleira morada em função da fertilidade do solo sob adubação mineral e orgânica. 2003. Dissertação (Mestrado em Manejo de Solo e Água) - Centro de Ciências Agrárias, Universidade Federal da Paraíba, Areia.

FOOD AND AGRICULTURE ORGANIZATION OF THE UNITED NATIONS - FAO. FAOSTAT: statistics database. Disponível em: <http://apps.fao.org/>. Acesso em 10 Jun. 2006.

GAIVA, N. H.; PEREIRA, W. E.; VALENTE, J. P.; CAMPOS NETO, J. D. D. Produção de duas cultivares de mamoeiro do grupo Solo sob dois sistemas de plantio e condições de irrigação. In: CONGRESSO BRASILEIRO DE FRUTICULTURA, 17, 2002, Belém. Anais... Belém: Sociedade Brasileira de Fruticultura, 2002. (CDROM).

GALBIATTI, J. A.; GARCIA, A.; SILVA, M. L. D.; MASTROCOLA, M. A.; CALDEIRA, D. S. A. Efeitos de diferentes doses e épocas de aplicação de efluente de biodigestor e da adubação mineral em feijoeiro-comum (Phaseolus vulgaris L.) Submetido a duas lâminas de água por meio de irrigação por sulco. Científica, Jaboticabal, v.24, n.1, p.63-74, 1996.

IBGE. Instituto Brasileiro de Geografia e Estatística. Levantamento sistemático da produção agrícola. Disponível em: <http://www.ibge.gov.br/>. Acesso em: 10 jun. 2006.

INSTITUTO ADOLFO LUTZ. Normas analíticas, métodos químicos e físicos para análise de alimentos. 3.ed. São Paulo: Instituto Adolfo Lutz, 1985. v.1.

KHATOUNIAN, C. A. A reconstrução ecológica da agricultura. Botucatu: Agroecologica, 2001.

LAGREID, M.; BOCKMAN, O. C.; KAARSTAD, O. Agriculture, fertilizers and the environment. Cambridge: CABI, 1999.

LEÃO, R. Z. R.; FAGUNDES, G. R.; YAMANISHI, O. K. Qualidade dos frutos de mamoeiro, cultivares Sunrise Solo e Tainung 1, produzidos nas regiões oeste e sul da Bahia. In: CONGRESSO BRASILEIRO DEFRUTICULTURA, 17. 2002, Belém. Anais... Belém: Sociedade Brasileira de Fruticultura, 2002. (CDROM).

MARINHO, C. S.; MONERAT, P. H.; CARVALHO, A. J. C.; MARTINS, S. L. D.; VIEIRA, A. Análise química do pecíolo e limbo foliar como indicadora do estado nutricional dos mamoeiros solo e formosa. Scientia Agrícola, Piracicaba, v.59, n.2, p.373-381, 2002.

MARINHO, C. S.; OLIVEIRA, M. A. B.; MONNERAT, P. H.; VIANNI, R.; MALDONADO, J. F. Fontes e doses de nitrogênio e a qualidade dos frutos do mamoeiro. Scientia Agricola, Piracicaba, v.58, n.2, p.345-345, 2001.
MEDINA, J. C.; GARCIA, J. L. M.; SALOMÓN, E. F. G.; VIEIRA, L. F.; RENESTO, O. V.; FIGUEIREDO, N. M.; CANTO, W. L. Mamão: da cultura ao processamento e comercialização. São Paulo: [s.n.], 1980. (Série 7).

MEIRELLES, L.; BRAGIOLINETO, A.; MEIRELLES, A. L.; GONÇALVES, A.; GUAZELLIS, M. J. Biofertilizantes enriquecidos: caminho sadio da nutrição e proteção das plantas. Ipê: CAE, 1997.

MIRANDA, S. P.; FAGUNDES, G. R.; MACHADO FILHO, J. A.; MORAES, A. V.; LIMA, L. A.; YAMANISHI, O. K. Caracterização física e química de mamões dos grupos Solo e Formosa cultivados em Brasília - DF. In: CONGRESSO BRASILEIRO DE FRUTICULTURA, 17 ., 2002, Belém. Anais... Belém: Sociedade Brasileira de Fruticultura, 2002. (CDROM).

OLIVEIRA, A. M. G.; CALDAS, R. C. Produção do mamoeiro em função de adubação com nitrogênio fósforo e potássio. Revista Brasileira de Fruticultura, Jaboticabal, v.26, n.1, p.160-163, 2004.

OLIVEIRA, M. A. B.; VIANNI, R.; SOUZA, G.; ARAÚJO, T. M. R. Caracterização do estádio de maturação do papaia Golden em função da cor. Revista Brasileira de Fruticultura, Jaboticabal, v.24, n.2, p.559-561, 2002.

PASTOR, M. C. R. Consideraciones sobre la utilización de diferentes densidades em el cultivo de papaya (Carica papaya L.) "Baixinho de Santa Amália" em Islãs Canárias. Revista Brasileira de Fruticultura, Jaboticabal, v.24, n.3, p.707-710, 2002.

SANTOS, A. C. V. Biofertilizante líquido: o defensivo agrícola da natureza. 2.ed. Niterói: EMATER-RJ, 1992. (Agropecuária Fluminense, 8).

SANTOS, H. G.; JACOMINE, P. K. T.; ANJOS, L. H. C.; OLIVEIRA, V. A.; OLIVEIRA, J. B.; COELHO, M. R.; LUMBRERAS, J. F.; CUNHA, T. J. F. (Ed.). Sistema brasileiro de classificação de solos, 2.ed. Rio de Janeiro: EMBRAPA, 2006.

SANTOS, R. H. S.; MENDONÇA, E. S. Agricultura natural, orgânica, biodinâmica e agroecológica. Informe Agropecuário, Belo Horizonte, v.22, n.212, p.5-8, 2000.

SOUSA, G. B.; MENEZES JÚNIOR, J. C.; MESQUITA, E. F.; ARAÚJO, F. A. R.; CAVALCANTE, L. F. Biofertilizante no solo e estado nutricional do mamoeiro baixinho de Santa Amália. In: CONGRESSO BRASILEIRO DE FRUTICUlTURA, 19., 2006, Cabo Frio. Palestras e Resumos... Cabo Frio: SBF/UENF/UFRuralRJ, 2006.

VILELLA JUNIOR, L. V.E.; ARAÚJO, J. A. C.; FACTOR, T. L. Comportamento do meloeiro em cultivo sem solo com a utilização de biofertilizante. Horticultura Brasileira, Brasília, v.2, n.2, p.153-157, 2003. 